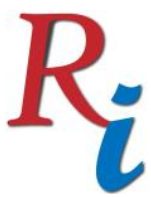
$\Gamma \Gamma$
S C I E N C E
$\mathrm{P} \mathrm{R} O$
$E E D \perp N G S$
S E R I E S
http://readersinsight.net/SPS

\title{
RECENT DEVELOPMENTS ON BIOMASS UTILIZATION FOR BIOENERGY PRODUCTION IN PAKISTAN
}

Salman Raza Naqvi*

School of Chemical \& Materials Engineering

National University of Sciences \& Technology

Pakistan

salman.raza@scme.nust.edu.pk

*Corrosponding author's Email: salman.raza@scme.nust.edu.pk

Peer-review under responsibility of 4th Asia International Multidisciplinary Conference 2020 Scientific Committee http://connectingasia.org/scientific-committee/ (C) 2020 Published by Readers Insight Publisher, Office \# 6, First Floor, A \& K Plaza, Near D Watson, F-10 Markaz, Islamabad. Pakistan, editor@readersinsight.net This is an open access article under the CC BY-NC-ND license (http://creativecommons.org/licenses/by-nc-nd/4.0/). 


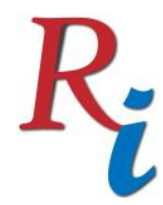

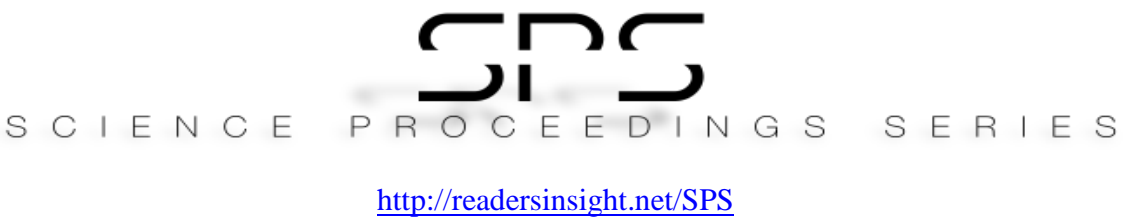

\section{A b s t r a c t}

Till to date, Pakistan is facing a shortage of electricity, unplanned electricity shutdown for several hours might be due to the endearment to fossil energy resources causing socioeconomic and environmental limitations. This study provides an overview of the recent bioenergy sector of the country and recent developments towards bioenergy production from renewable resources. This study also shows a deeper look of lignocellulosic biomass potential resources which could provide bioenergy by off-grid electricity on a larger scale. The study concludes that lignocellulosic residues are the favorable source of eco-friendly, implementable, viable and provides zero emissions bioenergy production in Pakistan.

Keywords: Biomass, Bioenergy, Developments, Pakistan

\section{Research High I ight s}

1. Study provides an insight into the potential of lignocellulosic bioass to bioenergy

2. Biomass is appeared as viable, sustainable and environmental-friendly resource for bioenergy in Pakistan

\section{Research Objectives}

This paper presents an overview of the generation of bioenergy in terms of bioenergy production by effective utilization of lignocellulosic residue as a cheap energy resources in the country by exploring alternative assessment in spite of fossil fuels. Our study concludes with ky findings and recommendations with alternative solutions which should be focused by estbalishing proposed policy framework for waste residue based power generation.

\section{Methodology}

In this paper, the data is collected from analysis purpose from various authorized resources such as Pakistan Economic surevey, Pakistan Council of Renewable Energy, Alternative Energy Development Board, articles, chapters and published data. The analysis is performed to overview the previous and forecast requirement of bioenergy potential. The viabale solutuon for this enery crisis in the country could solve through bioenergy blend perspective. The agricultural potential resources in the country for are identified and discussed as alternative transportation fuel. Lastly, based on the analysis and discussion, future policy recommendation are tabulated. Below is the scheme to propose the biomass flow process towards energy and materials production. 

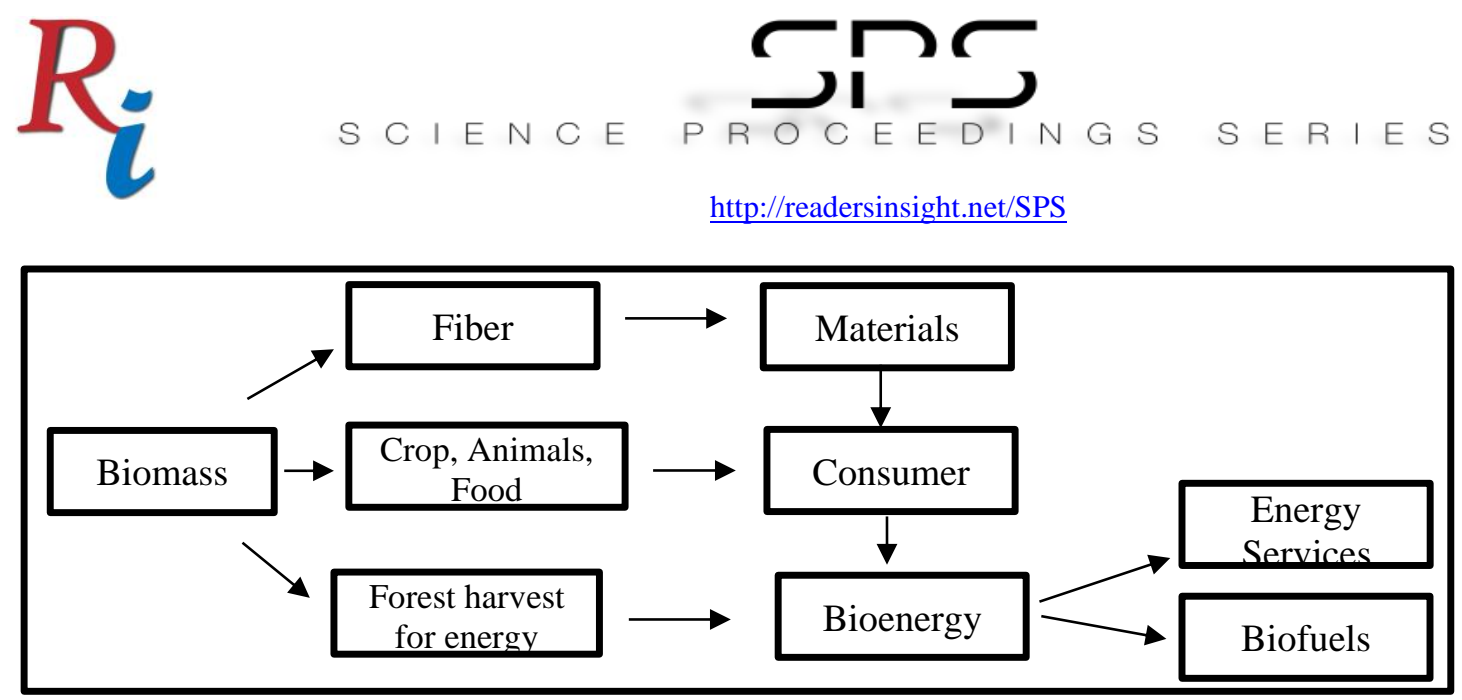

Fig. 1: Biomass processing flowchat towards bioenergy

\section{Results}

Biomass is appeared as potential environmental-friendly and viable option for bioenergy generation.

Resource (1-3). Various identified locations of residues, including crop \& animal wastes, and non edible residues possess the viability to produce electrcity through less greenhouse gases (Fig. 2) (4).

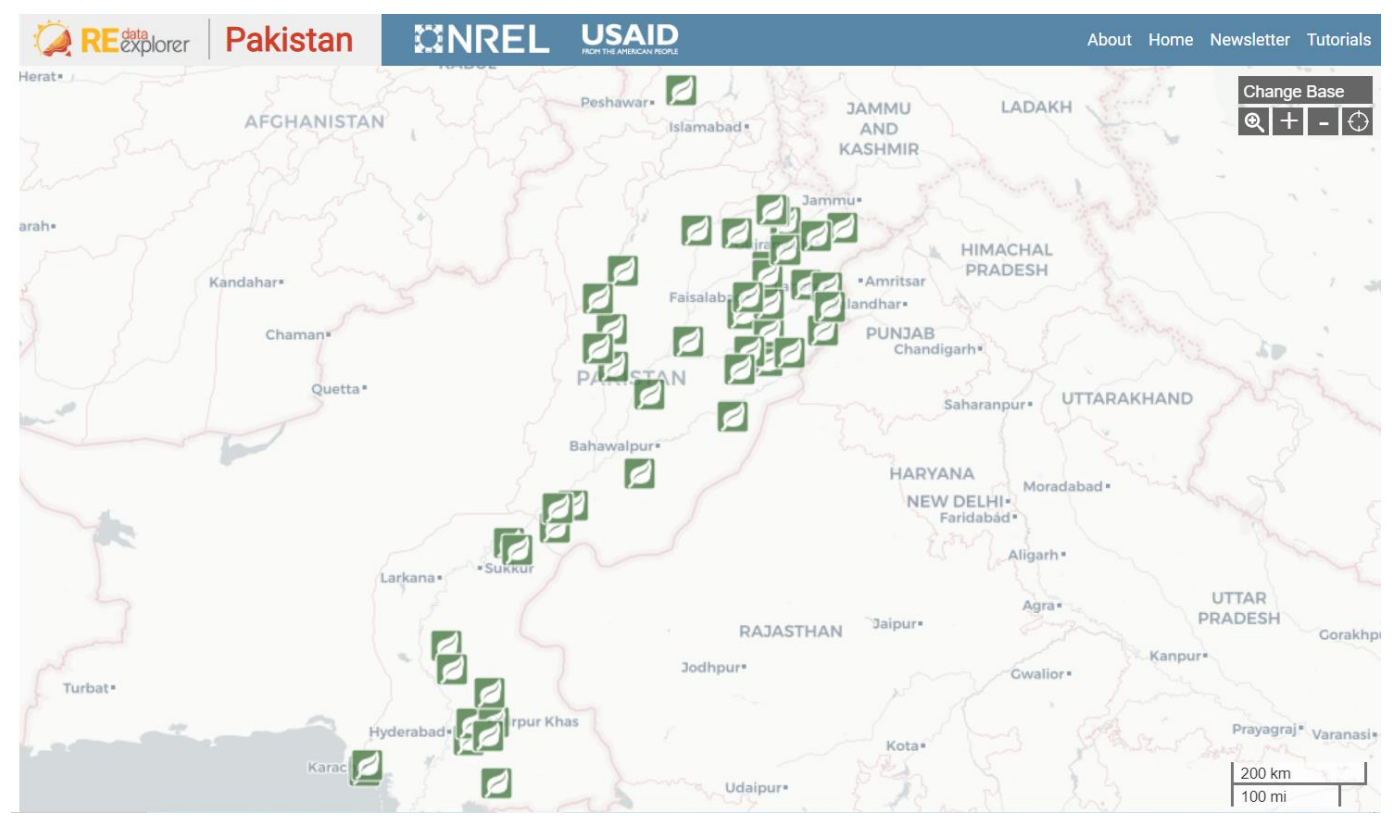

Fig. 2: Pakistan biomass agricultural resource (4)

The research research observation reveals that the there is a huge, abundant potential resources of agrivultural resources, animal wastes and solid wastes are available in the country. These alternatives resources appeared as the viable options for bioenergy production along with ecofrienly solution with very less greenhouse gases emissons (5). Wood can be utilized as cheap fuel which can meet the $48 \%$ of the domestic need. On the other hand, crop and animal wastes could meet the requirement of $32 \%$ of the energy demand. In the country, there are 85 industries 

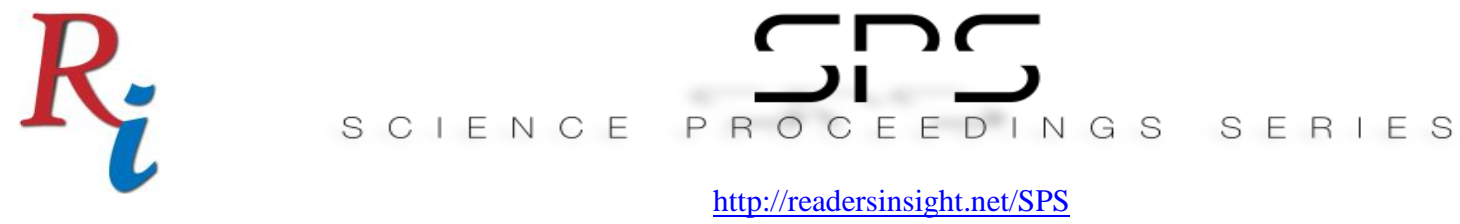

for producing sugar from bagasse. They are contributing electricity of $5800 \mathrm{GWh}$ to meet the requirment (6). There are five majore agricultural residues which are corn stalk, rice straw, bagasse, wheat straw, and cotton stalks. These residues are contirbuting towards the 6.43, 8.94, 17.86, 35.6, and 50.6 Mt of production, respectively. The estimated electricity power generation potential is approximately $5000 \mathrm{MW}$ from the animal wastes. On the similar basis, the solid municipal wastes potential are estimated for thermochemically \& biochemically are $560 \mathrm{kWh} / \mathrm{t}$ and $220 \mathrm{kWh} / \mathrm{t}$, respectively.

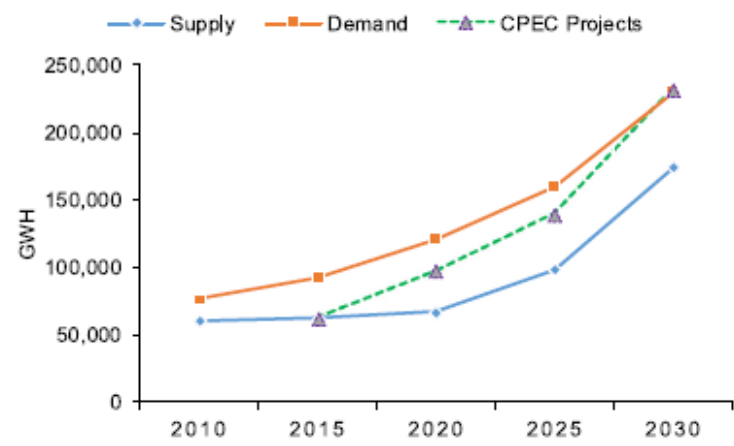

(a)

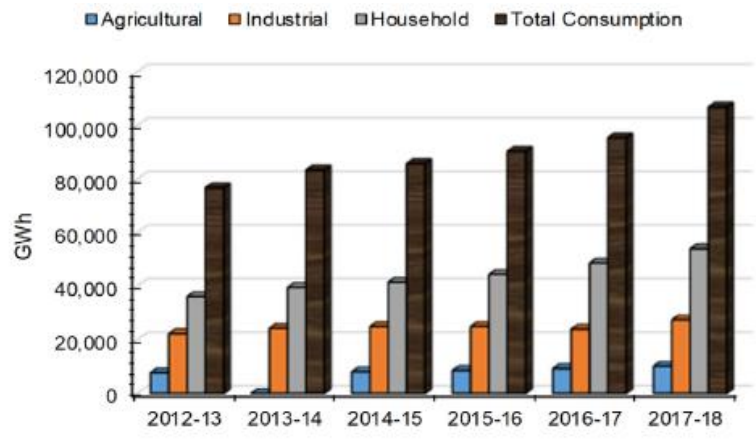

(b)

Fig. 3: (a) Electrcity demand-supply and CPEC project estimation, (b) sector-wise biomass contribution towards electricity generation(6)

\section{Findings}

As per the analysis, following policy recommendation should be considered for long term benefits by utilizing biomass resources for bioenery production (Table 1);

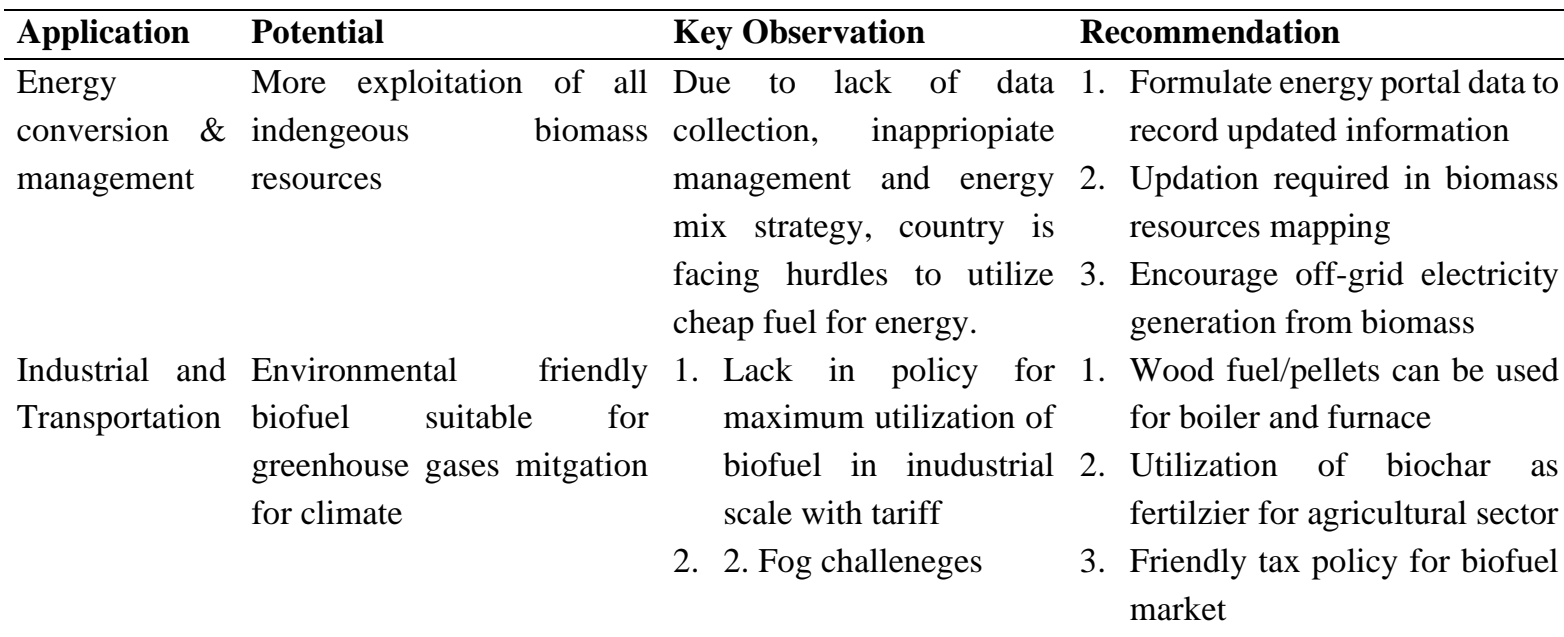

Power Biomass can produces the Power plants have to Micro-grid concept can be utilzied Production power of about $63 \mathrm{MW}$, adopted biomass fired in Pakistan for control, better producing a total of about power generation electricity production $146 \mathrm{MW}$ from bagasse-fuel technologies

built power plants, generating a total energy of $547 \mathrm{GWh}$. 

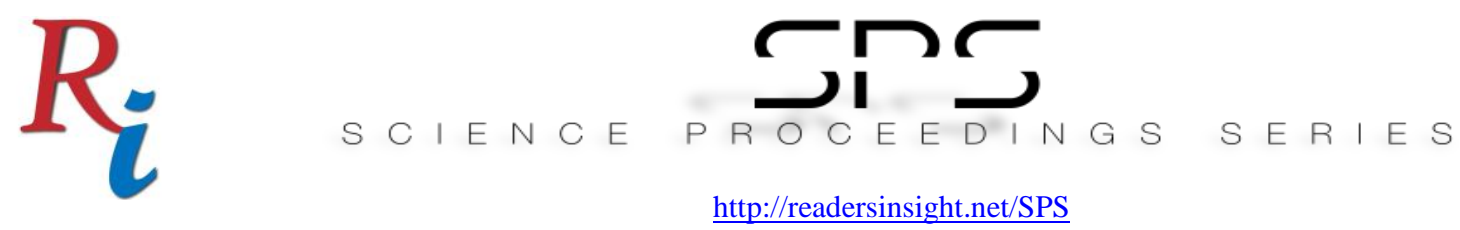

\section{Acknowledgement}

Author would like to acknowledge National University of Sciences and Technology for support.

\section{REFERENCES}

1. Naqvi SR, Jamshaid S, Naqvi M, Farooq W, Niazi MBK, Aman Z, et al. Potential of biomass for bioenergy in Pakistan based on present case and future perspectives. 2018;81:1247-58.

2. Shahbaz M, Al-Ansari T, Aslam M, Khan Z, Inayat A, Athar M, et al. A state of the art review on biomass processing and conversion technologies to produce hydrogen and its recovery via membrane separation. 2020.

3. Ubando AT, Chen WH, Tan RR, Naqvi SRJIJoER. Optimal integration of a biomassbased polygeneration system in an iron production plant for negative carbon emissions. 2019.

4. Gondal IA, Masood SA, Khan RJIJoHE. Green hydrogen production potential for developing a hydrogen economy in Pakistan. 2018;43(12):6011-39.

5. Farooq MK, Kumar SJR, Reviews SE. An assessment of renewable energy potential for electricity generation in Pakistan. 2013;20:240-54.

6. Irfan M, Zhao Z-Y, Panjwani MK, Mangi FH, Li H, Jan A, et al. Assessing the energy dynamics of Pakistan: Prospects of biomass energy. 2020;6:80-93.

Author's Biography

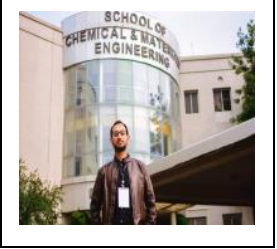

Dr. Salman Raza Naqvi is currently working as an Assistant Professor at the School of Chemical \& Materials Engineering, National University of Sciences \& Technology Islamabad, Pakistan. His research domain encompasses biomass \& bioenergy, biofuels production using thermochemical conversion processes and waste-to-energy projects, especially waste residues conversion to solid, liquid and gaseous fuels. He worked at BASF SE Germany in process engineering department after completing MSc Chemical Engineering from Technical University Dortmund, Germany. Dr. Naqvi has published more than 53 impact factor journal papers with citation around 610 and H-index equal to 16. 